\title{
CAMBIOS, PERVIVENCIAS Y ADAPTACIONES. LA INTEGRACIÓN DE LAS ÉLITES NATIVAS EN EL VIRREINATO DE PERÚ DURANTE EL SIGLO XVI
}

CHANGES, REMINISCENCES AND ADAPTATIONS. THE INTEGRATION OF THE

NATIVE ELITES IN THE VICEROYALTY OF PERU DURING THE XVI CENTURY

Alejandro Leiva Arcas ${ }^{1}$

Universidad Católica de Murcia, Guadalupe, Espanha.

\begin{abstract}
Resumen: Tras la conquista del imperio inca por parte de los soldados españoles, dio comienzo un proceso de articulación social y de gobierno del espacio andino. Con el fin de establecer un control efectivo sobre el territorio, las élites españolas negociaron con los líderes indígenas su nuevo rol en la sociedad emergente. Este artículo explora cómo los caciques andinos asumieron este cambio y cómo ejercieron sus mecanismos de poder para consolidar, reconfigurar y aumentar su estatus en el nuevo orden colonial.
\end{abstract}

Palabras clave: Caciques; Vicerreinato de Perú; Etnohistoria.

Abstract: After the conquest of the Inca empire by the Spanish soldiers, began a process of social articulation and government of the Andean space. In order to establish effective control over the territory, the Spanish elites negotiated with the indigenous leaders their new role in the emerging society. This article explores how the Andean caciques assumed this change and how they exercised their power mechanisms to consolidate, reconfigure and increase their status in the new colonial order.

Keywords: Caciques; Viceroyalty of Perú; Etnohistory.

${ }^{1}$ Professor, Facultad do Esporte da Universidad Católica de Murcia. E-mail:aleiva@ucam.edu. 


\section{INTRODUCCIÓN}

Entender el funcionamiento de la sociedad indígena en época colonial conlleva, necesariamente, comprender el poder que detentaban sus élites y el uso que hacían del mismo para reivindicar su posición de prestigio en la nueva jerarquía social que se había configurado en el espacio andino desde la Conquista. Estas élites, personificadas en los caciques, desarrollaron un papel fundamental para el funcionamiento de la Colonia al servir de nexo de unión entre las autoridades españolas y el conjunto de la población indígena que gobernaban.

La historiografía ha prestado una gran atención a la nobleza nativa, especialmente a aspectos relacionados con su riqueza patrimonial, estatus jurídico, liderazgo espiritual o su trascendencia en la explotación económica - especialmente minera - del espacio andino. Sin embargo, pocas veces se ha recurrido al análisis cruzado de estos factores para entender el verdadero estatus de los caciques desde un enfoque holístico. A través del estudio polisémico de la figura de los señores étnicos y del poder que detentaron, desvelaremos que si bien la Conquista produjo un cambio dramático en las jerarquías de poder incaicas radicadas en Cuzco, en el caso de la nobleza nativa regional pudo conservar su estatus de poder e incluso contar con nuevas oportunidades para acrecentar su prestigio, autoridad y riqueza en el nuevo orden colonial.

Abordar el estudio de la figura del cacique en la América colonial hispana implica entender tanto el desarrollo del cargo a nivel político como al individuo que ejerce el poder asociado a tal función. Partiendo de que la Historia está constituida por sujetos (FOUCAULT 1988), y que tales sujetos operan como actores individuales cuyas acciones tienen una implicación directa en el cambio social (PONCE LEIVA, 2011), en nuestro estudio, trataremos de desvelar cómo los caciques ejercían las cuotas de poder que poseían desde su delicada posición de equilibrio entre ambos mundos a través de las herramientas políticas y legales que tuvieron a su alcance. Se trata, por tanto, de una aproximación a estos líderes poniendo especial énfasis en sus pretensiones, conductas y actitudes dentro de un contexto cambiante y ambivalente. Por ello, es preciso valorar los diferentes espacios virreinales en los que actuaron, y que otorgaron a los caciques una trascendencia social destacable más allá de la apariencia de su categoría social o de su cargo político-administrativo (POLONI-SIMARD, 2005). 


\section{LAS ÉLITES NATIVAS EN EL NUEVO ORDEN COLONIAL}

Con la irrupción de los españoles en el espacio andino y tras el consiguiente proceso de conquista militar y de implantación de la estructura jurídico-administrativa colonial, la nobleza indígena, lejos de extinguirse, consiguió incorporarse de manera paulatina en los nuevos parámetros sociales, manteniéndose en el nivel superior dentro de la población india y cumpliendo una función semejante a la que desarrollaban en tiempos del Inca (GAREIS, 2007). Los caciques lograron conservar esta posición de poder al emerger como piezas claves en la consolidación de los nuevos esquemas virreinales de control sobre la población autóctona, especialmente en lo referente a la extracción de minerales y en la recolección del tributo. Por este motivo, desde los primeros años de dominio colonial, los señores étnicos desempeñaron un papel fundamental en lo que Martín Monsalve ha denominado el "estilo indirecto de gobierno que la administración virreinal llevó a cabo en los Andes" (MONSALVE, 2003, p. 160).

Debido a su importancia como nexo de unión con la población india, las autoridades hispanas ratificaron la posición social de los caciques mediante el reconocimiento explícito de su nobleza. De este modo, se reconoció su autoridad previa a la Conquista sobre el resto de indios del común al equiparar su estatus al de los hidalgos castellanos (DÍAZ DE REMENTERÍA, 1977). Ahora bien, la Corona únicamente reconoció la nobleza de los caciques principales. Si bien un cacique principal estaba al frente de todo un repartimiento, no lo estaba a su vez de aquellos pueblos o parcialidades que lo componían, gobernados por caciques de un rango menor descritos en la documentación como segundas personas. A pesar de estar en el nivel más alto de la jerarquía nativa, los caciques principales gobernaban a sus sujetos desde una posición superior pero, al mismo tiempo, ajena a ellos (DE LA PUENTE LUNA, 2007). Al no poder controlar directamente las parcialidades de sus repartimientos, los caciques principales estaban obligados a negociar constantemente con los caciques de un nivel inferior cuya nobleza no había sido reconocida por los españoles. Esta desvinculación generaría una evidente falta de cohesión que mermaría el equilibrio en el interior de los curacazgos. Al depender de los caciques subordinados y buscando un respaldo firme para su autoridad ante los indios, los caciques principales contaron con dos alternativas: realizar un acercamiento progresivo hacia las autoridades virreinales, hispanizándose y convirtiéndose en agentes coloniales; o bien acrecentar la proyección interna de su poder mediante la 
reafirmación de su autoridad frente a sus sujetos. Ambas circunstancias tuvieron lugar y deben de ser tenidas en cuenta para comprobar que el ejercicio de la autoridad por parte de los caciques no fue un fenómeno único ni unidireccional, sino que destacó por su capacidad de adaptación ante el amplio catálogo de situaciones diversas que tuvieron lugar durante el periodo de consolidación colonial.

Los curacazgos no eran, por tanto, espacios homogéneos en los que no faltaban las tensiones internas y las rupturas. La propia dinámica colonial provocó que el ejercicio de poder en los mismos estuviera plagado de incidencias. A la ya citada superposición de jerarquías locales se deben unir otros factores como el descenso demográfico que afectó a la población indígena (incluidas las élites andinas), la sustitución de aquellos caciques que no eran leales a la Corona por otros más dispuestos a colaborar con los españoles y, finalmente, el desmembramiento de los señoríos en encomiendas, quedando divididos en repartimientos en los que se integraban diversas comunidades que habían sido previamente reducidas, creando nuevos contextos de interetnicidad marcados por la pérdida de adscripción territorial (RAMÍREZ, 1997; ASSADOURIAN, 1994). Si en estas circunstancias el ejercicio de la soberanía nativa debía de ser ya de por sí complicado, cabe añadir un hecho de trascendentales consecuencias como fue el menoscabo de sus competencias de gobierno ante la llegada de nuevas autoridades de origen español como fueron los encomenderos, los corregidores y los curas doctrineros.

En los primeros años de colonia, los caciques pudieron mantener e incluso aumentar su autoridad debido a la débil presencia del clero y a la connivencia de los cargos políticos hispanos, especialmente de los encomenderos (GRAÑA, 2001). De hecho, algunos autores como MoniqueAlaperrine-Bouyer afirman "que los caciques fueron aceptados y respetados en un primer momento al ser tratados como una "curiosidad exótica", desarrollándose una colaboración ideal, aunque efímera, entre las autoridades nativas y españolas"'(ALAPERRINE-BOUYER, 2005, pp. 191-192). No obstante, a medida que la estructura colonial se iba asentando en el territorio peruano, la imagen positiva de los caciques se fue deteriorando progresivamente. Entre 1550 y 1560 se recogen numerosas quejas de los agentes de la administración, clérigos y encomenderos acusando a los caciques de estar entorpeciendo sus funciones; conviene precisar que no ponían en cuestión la legitimidad de su poder, sino la forma en que ejecutaban el mismo. 
En respuesta a esta situación, en 1565 la Corona decretó dos importantes medidas destinadas a reducir el poder de los señores nativos: la separación de los títulos de gobernador y cacique, y la creación del cargo de corregidor de indios (ASSADOURIAN, 1994). Si bien la primera no tuvo especial trascendencia debido a que muchos caciques continuaron ostentando el título de gobernador, la segunda si produjo una merma efectiva de la autoridad caciquil en el ámbito local. Con la creación del cargo de corregidor de indios se consiguió aumentar la presencia del aparato burocrático español en el seno de las comunidades indígenas y establecer un contrapunto que sirviera de control al poder de los caciques, algo que sin duda sucedió.

La política de menoscabo de la autoridad nativa no había hecho más que comenzar. Tras un periodo de marcada inestabilidad en el espacio virreinal, arribó a las costas de Perú en 1569 el que iba a ser el quinto de virrey de Perú y uno de los mayores reformadores de su historia colonial, don Francisco Álvarez de Toledo. Toledo llegó a Perú con propósitos bien definidos entre los que se encontraban mejorar el rendimiento de la producción minera, fortalecer la labor evangelizadora o consolidar la estructura fiscal y administrativa. En el desarrollo de estos planes se encontraban irremediablemente los caciques andinos. El virrey era consciente de que para llevar a cabo sus reformas debía contar con el apoyo de las autoridades étnicas pero limitando al tiempo su poder para evitar que interfirieran en sus propósitos. Dicha limitación se hizo presente cuando en 1572 Toledo creó la figura del alcalde de indios restringiendo considerable las competencias de los señores étnicos dentro del aparato administrativo colonial, quedando éstas reducidas a la recolección del tributo y a la organización de la mita minera en aquellas provincias donde estuviera vigente este sistema de rotación laboral (ASSADOURIAN, 1994). No obstante, el virrey Toledo era consciente de que para implantar su estrategia de dominio sobre el territorio andino necesitaba contar con la cooperación y el apoyo de los líderes indígenas como condición necesaria para el control del resto de la masa india. Por ello, sus reformas debían ofrecer una contrapartida y ante esa pérdida de competencias los caciques obtuvieron ciertas compensaciones que respaldaban su lealtad y les ayudaban a conservar y hacer efectivo su poder (SPALDING, 1981). A cambio de realizar las funciones que la administración española les había asignado, los caciques obtuvieron el derecho a recibir un salario procedente de las tasas que ellos mismos recaudaban, en forma de dinero, ropa, coca o ganado, o de manera alternativa, en forma de 
servicios personales de sus sujetos (DÍAZ DE REMENTERÍA, 1977). La cuestión ineludible llegados a este punto es comprobar si tales prestaciones fueron suficientes.

\section{LA DOBLE PROYECCIÓN DEL PODER NATIVO}

Cuando el virrey Toledo abandonó Perú en el año 1581, los caciques andinos se encontraban en una posición definida pero complicada. Por una parte habían logrado el reconocimiento del estatus de nobleza con los privilegios que esa situación conllevaba: exención del pago de tributo y de acudir a la mita en calidad de mitayo, abstención de ir a la cárcel por deudas civiles y el permiso para poner bajo su servicio a los indios no visitados entre otras prerrogativas (BUNSTER, 2001). Por otra parte, los caciques se convirtieron en agentes coloniales para llevar a cabo los proyectos fiscales y organizativos de la Monarquía Hispánica, lo cual les dejaba en una situación delicada. Debían de buscar el equilibrio para satisfacer las demandas de la administración virreinal, como respaldo legal a su poder, al tiempo que debían cumplir con las expectativas de los indios a su cargo en lo referente a la preservación de la tradición andina, la defensa de sus intereses como comunidad y, ante todo, al buen gobierno que debían ejercer en el interior de los ayllus (SÁNCHEZ ALBORNOZ, 1978). Se trataba, por tanto, de una basculación para ejercer su autoridad de manera efectiva sin romper las condiciones de legalidad, impuestas desde el mundo hispano, y sustentada sobre la legitimidad que emanaba de sus sujetos y necesaria para su reconocimiento interno como líder. Esta doble autoridad, basada en el prestigio andino que era distinto, pero igual de necesario, al reconocimiento que le otorgaba el sistema judicial colonial. La clave del éxito pasaba por la consolidación de un espacio de poder propio entre ambos mundos tan diferenciados, pero intrínsecamente unidos (PACHECO BALANZA, 2012).

No obstante, ¿cómo se materializaba esta autoridad dual en la práctica? Comencemos con las formas en que los caciques desarrollaban el poder dentro de sus pueblos. La soberanía, en las sociedades andinas era conferida por la propia comunidad a cambio de servicios prestados buscando el interés solidario comunal. Un buen dirigente era obedecido y servido por sus sujetos en retribución a su función como protector de las normas y las tradiciones locales y como buen gestor de los recursos humanos y materiales de su comunidad (SPALDING, 1981). El reparto de tierras, el mantenimiento de los derechos de los miembros del ayllu, la mediación en conflictos personales o comunitarios, la administración y 
distribución de recursos como el agua o los alimentos; el control contable de la caja de comunidad; la regulación del intercambio recíproco para la subsistencia básica del grupo (llamado ayni), del trabajo colectivo en favor de la comunidad (minca) o del intercambio ceremonial (ROSAS LAURO, 2009). El cacique debía igualmente velar por los derechos de cada miembro de su comunidad, asegurándose de que nadie usufructuara más de lo correspondido de las tierras o bienes comunes, vigilar el esquileo anual de las llamas y la gestión de las parcelas agrícolas, así como procurar el mantenimiento de los ritos y respaldar las demandas hechas por los miembros menos prósperos (SPALDING, 1974, 1981). De cara al exterior, la función más importante de los señores étnicos era la de representar a su comunidades y hacer valer sus intereses ante las autoridades virreinales. Un ejemplo de ello lo encontramos durante el proceso reformista del virrey Toledo. Como hemos visto, para llevar a cabo su estrategia, el virrey tuvo que contar con la participación de los señores étnicos. Para granjearse su apoyo, Toledo negoció con los caciques andinos acordando la ubicación de las nuevas reducciones y asegurando su acceso a los múltiples pisos ecológicos para obtener los recursos complementarios que necesitaban. Además, los caciques lograron conservar parte de la mano de obra para sus ayllus, la cual comenzaba a ser un bien preciado por la crisis demográfica, así como obtener acceso a ciertos cargos que implicasen una mayor cuota de poder político, como el de Capitán de Mita o Alcalde de Indios (GRAÑA, 2001).

En lo que respecta al ejercicio de la autoridad en el ámbito colonial español, ya hemos visto cómo Toledo redujo las funciones de los caciques a la recaudación tributaria y a la organización de los turnos de la mita. Respecto a la primera de estas competencias - la exacción fiscal - los caciques principales eran los responsables últimos de que los impuestos que se debían recaudar en el seno de sus comunidades, aunque el acto físico de recoger los tributos recayese en jefes de menor escala descritos en la documentación con el término de caciques de tasa.

La cuantía de los tributos se fijaba en función de un padrón llamado tasa, elaborado en relación a la población tributaria existente - varones sanos de entre 18 y 50 años - y realizado periódicamente por un agente de la administración específico llamado visitador general. La visita y numeración de los tributarios debía realizarse en todo momento en presencia del cacique principal, quien debía presentar el último padrón elaborado para su cotejo con los 
libros de bautismo y defunción que presentaban los curas, para evitar ocultaciones y fraudes. Una vez realizado el nuevo padrón, se entregaba una copia al cacique en donde se indicaba la cantidad total a tributar. Era además, un gesto simbólico que indicaba el estar adquiriendo un compromiso de pago hacia la hacienda real. La responsabilidad de cobrar los tributos pasaba entonces a manos del cacique. Dicha recaudación tenía lugar dos veces al año, durante las festividades de San Juan (junio) y Navidad (diciembre). La recaudación directa de los tributos era llevada a cabo por los caciques de tasa, los cuales podían hacerse efectivos en forma de dinero o especies ${ }^{2}$. Una vez recopilado, hacían entrega del mismo al cacique principal quien debía, a su vez, transferirlo al corregidor (DE LA PUENTE LUNA, 2007).

No obstante, como garantía de pago, el cacique había desembolsado previamente una fianza igual al monto total de los tributos a recaudar. Dicha fianza provenía de su patrimonio personal o si no disponía del dinero suficiente, de la caja de comunidad. Este depósito obedecía a un doble fin: asegurar el pago de los tributos e incentivar a los caciques a recaudar las tasas al tener que cubrir con su propia riqueza, o la de sus comunidades, los impagos. Además, los caciques contaban con medios legales para poder cobrar los tributos de manera firme a los indios morosos. En caso de la negativa de un indio a contribuir, los señores tenía potestad para ejercer sobre él acciones coercitivas o incluso enviarlo a prisión hasta que hiciera efectivo el pago. Igualmente, el cacique tenía autoridad para reducir a los indios a su cargo que hubieran huido de sus comunidades para no tributar. Cualquier ardid de los caciques con fines fraudulentos, como la falsificación de los datos del padrón, la negativa a colaborar con los agentes reales o la ocultación premeditada de indios tributarios, significaban automáticamente le pérdida del título que ostentaban (DÍAZ DE REMENTERÍA, 1977).

Es fácil imaginar que la posición en la que se encontraban los caciques era cuanto menos comprometida. La recaudación tributaria era una de las máximas prioridades de la administración colonial y la base económica del sustento virreinal y por ende, de la Monarquía Hispánica. Los caciques eran el eslabón fundamental para llevar a cabo el cobro. de los mismos, lo que sin duda les situaba en una situación delicada. El no satisfacer las exigencias del Estado significaba tener que responder con su propio patrimonio personal y, en

\footnotetext{
${ }^{2}$ Para la región de Huamanga, Perú, Steve J. Stern, ha especificado que los tributos entregados por los indios,
} además de dinero, eran plata, paños, maíz, trigo, patatas, cerdos, calzado o pollos. (1982, p. 137 - Cuadro 4.2.) 
el peor de los casos, sufrir la pérdida del título de cacique. Por otra parte, el abuso de poder para llevar a cabo la exacción fiscal les podía acarrear el resentimiento de sus sujetos con la consiguiente pérdida de legitimidad. Además, el hecho de depender indirectamente de la labor recaudatoria de los caciques de tasa, les restringía el control sobre esta situación.

La organización de la mita era la segunda de las grandes responsabilidades de los señores nativos para con la administración virreinal. Durante la década de 1570, Francisco de Toledo diseñó un sistema de trabajo en turnos rotativos para racionalizar la explotación de centros mineros como Potosí, Oruro, Porco o Huancavelica. Inspirándose en la mit'ade origen incaico, Toledo estableció un sistema por el cual una séptima parte de los tributarios varones de cada repartimiento debían acudir durante un período de 2 a 4 meses a trabajar como mineros o en otros oficios asociados a esta actividad (STERN, 1982). A pesar de ser un trabajo forzoso, los mitayos recibían una retribución por su trabajo. Además, el sistema rotativo favorecía que un indio sólo acudiera a la mita una vez cada seis o siete años (LÓPEZBELTRÁN, 1991). De hecho, no todos los repartimientos estaban obligados a aportar mitayos; para la explotación del Cerro Rico de Potosí, se establecieron 16 regiones mitayas, quedando otras muchas exentas ${ }^{3}$.

La reunión, desplazamiento y control de los mitayos era competencia del Capitán de Mita, cargo administrativo creado por Toledo para la gestión de los mismos. Existían dos categorías: los capitanes generales de provincias, nombrados entre los caciques principales; y los capitanes chicos, nombrados entre las segundas personas de los repartimientos (CHOQUE CANQUI, 1983). Los primeros eran los máximos responsables de que los turnos de trabajo se cumplieran de manera satisfactoria, mientras que los segundos realizaban las tareas directas de control de los mitayos. Además, contaban con alguaciles para hacer cumplir sus decisiones y quipucamayoc, indios especializados en la contabilidad a través de quipus para facilitar el trabajo (GRAÑA, 2001).

No es competencia de este trabajo desgranar las vicisitudes del desarrollo de la mita durante sus más de dos siglos de existencia, pero sí nos vamos a profundizar en cuáles fueron

\footnotetext{
${ }^{3}$ Son Condes, Cann, Canchi, Uma, Urco, Paucar, Lupaga, Pacajes, Sora, Quillaca, Caranca, Chayanta, Caracara, Chicha, Paria y Cochabamba, según López Beltrán (1991, p. 64)
} 
sus implicaciones respecto al ejercicio del poder y la autoridad de las élites nativas que participaron en ella. A pesar de que el cargo de Capitán General de Provincia era rotativo, las ventajas que ofrecía dicho puesto (residencia permanente en Potosí, mayor salario, mayor poder efectivo y mayores oportunidades para el enriquecimiento personal), provocó que hubiera una gran competencia para monopolizarlo. De hecho, hay constancia de que algunos lo consiguieron monopolizar, como es el caso de Gabriel Fernández Guarachi, cacique principal de Jesús de Machaca, en Pacajes (cerca de La Paz), quien fue elegido en 18 ocasiones para desempeñar el puesto (SAIGNES, 1987). El hecho de obtener una residencia en Potosí a través del cargo de Capitán General de Provincia no era un asunto baladí. Con el incremento de la actividad minera en Potosí, se había producido un desplazamiento de la noción de centro (entendido en términos de importancia política) desde Cuzco hacia la Villa Imperial, que rápidamente se convirtió en la ciudad más importante del virreinato de Perú junto con Lima. El desplazamiento de señores étnicos de relevancia a Potosí convirtió a la ciudad, en palabras de Thierry Saignes, "en una suerte de corte neo-inca”(SAIGNES, 1987, p. 152). Desde allí, los caciques fueron capaces de conseguir mejores condiciones para sus comunidades, no sólo en lo referente a la mita, sino en otros aspectos, como la lucha contra los abusos de las autoridades o la consecución de un mejor abastecimiento de sus ayllus. Además, el hecho de encontrarse más cerca de las autoridades españolas, permitió a los caciques interceder por los intereses de sus sujetos de manera personal; un ejemplo de ello lo encontramos en el "Padrón de Mitayos de 1600" conservado en el Archivo de la Casa de la Moneda de Potosí:

En Potosí a diez y ocho de mayo de mil seiscientos años ante don Álvaro Patiño, teniente de corregidor [...] don Martín Cumba, principal de Pomata [al suroeste del lago Titicaca] dijo que de los indios que hay en esta Villa [...] sin obligación de la mita, siete de los que son contenidos en la memoria de esta otra parte quieren quedarse en ella para servir en la mita del año venidero de mil seiscientos uno (ARCHIVO HISTÓRICO, CAJAS REALES 72, p.75).

Este texto es interesante de analizar por un doble motivo. En primer lugar permite comprobar como los caciques interactuaban en pos de los intereses de sus sujetos ante las autoridades españoles, revelando de este modo una de sus funciones de representación dentro de la estructura colonial. En segundo lugar, observamos que si bien la mita era un sistema que 
muchos indios trataron de evitar mediante la huida a otras provincias, muchos otros lo consideraban como una verdadera oportunidad para prosperar social y económicamente e incluso solicitaban la renovación de su condición de mitayos como podemos observar en el párrafo anterior.

No obstante, la tónica general no era ni mucho menos solicitar la asistencia voluntaria para servir como mitayo. A pesar de que los sueldos eran atractivos (unos 9 pesos diarios en 1600), la fuerte intensidad del trabajo minero y las precarias condiciones de seguridad, provocaron que muchos indios se ocultasen para evadir la obligación de la mita. Al igual que ocurría con la recaudación de tributos, era competencia de los Capitanes Generales el perseguir a los indios huidos o, en caso de no encontrarles, pagar la tasa correspondiente por su ausencia. De nuevo, en el "Padrón de Mitayos" se deja perfectamente claro cual era la manera de actuar en caso de que ocurrieran tales abstenciones:

\begin{abstract}
Si fuesen o ausentaren, o pudiesen a su costa mingar a otros en su lugar [...] los principales se hicieran cargo de los indios en dichas memorias contenidas y los exhibieran personalmente y asistieran con ellos en el contrapadrón que en esta Villa se hiciere por la justicia mayor de ella sin falta alguna. Y para el cumplimiento y entrega de ello [...] le dieron el poder de la justicia de su majestad de cualquier parte ante quien esta razón le compela (ARCHIVO HISTÓRICO, CAJAS REALES 72, p.90).
\end{abstract}

En otras palabras, la administración colonial daba potestad legal a los cacique con rango de Capitán General de Provincia para llevar ante la justicia española a los mitayos que huyesen de sus responsabilidades, algo fundamental para la mantención del sistema puesto que la fuga de mitayos fue un problema endémico durante los siglos XVI y XVII y los Capitanes de Mita eran, a ojos de las autoridades virreinales, los agentes mejor capacitados para combatir esta circunstancia. La fuga de mitayos tuvo que suponer un verdadero quebradero de cabeza para los Capitanes. Por ejemplo, en 1594, el Capitán General de los indios de la provincia de Pacajes, Juan Bautista Quispesala, reportó un total de 558 indios faltos. El problema no se limitaba únicamente al hecho de tener que buscar y entregar ante la justicia a los huidos, sino que esta situación provocaba el retraso del resto de mitayos que debían de acudir a las minas. El ya citado Gabriel Fernández de Guarachi, a lo largo del siglo 
XVII, se quejó en repetidas ocasiones del gran gasto que suponía para sus propias arcas el tener que buscar a los indios ausentes o el tener que mingar a otros para reponer las bajas, cuando no pagar las tasas por las ausencias (CHOQUE CANQUI,1983). Aún con todo, a pesar del evidente coste económico y los presumibles disgustos para los curacas que debían realizar labores de búsqueda y captura de los mitayos que decidían escapar, el cargo de Capitán General de mita seguía siendo muy codiciado. Si bien es cierto, que a medida que avanzaba el siglo XVII, únicamente los caciques con mayor solvencia económica aspiraban a tal puesto, debido a que las ausencias precisaban de la riqueza suficiente como para hacer frente a los gastos derivados de las huidas, seguía siendo muy pretendido por los caciques principales más importantes. La pregunta obligada es ¿por qué?.

A diferencia de lo que ocurría con el deber de recaudar el tributo, la función de organizar la mita a través de la capitanía granjeaba a los caciques más beneficios que problemas. Mientras que la tarea de exacción fiscal ponía en una posición complicada a los señores nativos, tanto frente al Estado como frente a sus sujetos, la Capitanía General de la mita otorgaba un poder efectivo del que los caciques podían sacar un buen rédito. En primer lugar, el poder acudir, e incluso residir en Potosí acercaba a los caciques a las altas autoridades españolas. Este hecho implicaba varias ventajas. En el proceso de consolidación de la autoridad de las élites nativas en el entramado colonial, el aproximarse a los círculos de prestigio hispanos era una estrategia altamente efectiva. La creación de vínculos mediante la interacción cotidiana con las autoridades españolas afianzaba el estatus de los caciques en la jerarquía virreinal. Además, el convivir en los mismos espacios que los españoles que ostentaban altas cotas de poder dentro de la sociedad, provocaba un aumento del prestigio nativo por asimilación. No sólo el residir en un gran centro urbano como Potosí tenía repercusiones positivas en el ámbito político. El ubicarse en uno de los principales centros económicos americanos propició que los curacas contasen con mayores oportunidades para enriquecerse a título personal, al insertarse progresivamente en el comercio de los mercados coloniales (SAIGNES,1987). Sirva de ejemplo el caso de don Carlos Vissa, cacique principal de Ácora (Puno) y Capitán General de los mitayos de Chucuito. En el "Padrón de Mitayos de 1600”, su nombre es, con diferencia, uno de los que más se repiten a lo largo del documento, reflejando una fuerte implicación con el funcionamiento de este sistema de extracción minera. Sólo un año después, en 1601, don Carlos Vissa realiza una importante donación al virrey 
Velasco de la sorprendente cantidad de 100.000 pesos para fortalecer la Armada colonial. En recompensa, el virrey le autorizó a portar daga, espada y a llevar consigo un séquito de alabarderos cuando se desplazase por los caminos, símbolos de prestigio de alto valor al estar reservados únicamente a la población española (MONSALVE, 2003). Sea por relación directa o indirecta, el cacique Vissa no sólo fue capaz de amasar una importante fortuna a través de su vinculación con el desarrollo de la mita, sino que consiguió establecer importantes lazos llegando hasta el mismísimo virrey. El hecho de recibir prebendas por su colaboración con la defensa militar del virreinato está revelando que está relación de favores actuó en ambos direcciones. El poder económico, por tanto, estaba complementando con los vínculos sociales que derivaron, en última instancia, en un fortalecimiento del poder simbólico del cacique a través del derecho adquirido de portar símbolos de poder tan necesarios como efectivos para ostentar la autoridad en una sociedad en la que lo visual primaba sobre lo escrito.

\section{LA BÚSQUEDA DE LA CONSOLIDACIÓN DE LA AUTORIDAD}

Hemos visto que a medida que el sistema colonial se fue arraigando en el espacio andino, los caciques fueron logrando afianzar su posición de poder y prestigio en un doble contexto político y social. Sin embargo, lejos de conformarse con esta situación, comenzaron a elevar numerosas quejas reivindicando la merma que habían sufrido en su autoridad y reclamando la restitución de las competencias y poderes perdidos en comparación con la situación que disfrutaron sus antepasados durante el imperio incaico. Esta actitud es cuanto menos interesante y debe de ser analizada con detalle para comprender la proyección política de los caciques en el ámbito virreinal peruano. Algunos autores como Karen Spalding (1974), a raíz de estos comportamientos, han calificado a los caciques como escaladores sociales. A nuestro entender, el término escalador social deja entrever que los señores étnicos se encontraban en una posición social inferior a la que verdaderamente gozaban y que por tanto, la necesidad de escalar respondería a una lidia constante por mejorar su posicionamiento en la jerarquía social y hacer mella en las instituciones virreinales. Nuestra postura es sensiblemente diferente. Consideramos que los caciques se encontraban en una posición consolidada, de prestigio, habiendo conseguido mantener su poder efectivo sobre sus sujetos y adquiriendo un papel relevante en el funcionamiento de la colonia. Sin embargo, a pesar de estos logros, los caciques mostraron una actitud inconformista, tratando tenazmente de mejorar su estatus y 
prestigio de acuerdo con los patrones jerárquicos imperantes entre la aristocracia española en la América colonial hispana. Creemos que el concepto de escalador no debe de ser confundido con el de ambición, cualidad que parece inseparable de la figura de los caciques andinos.

Como líderes civiles y políticos, los señores étnicos aspiraban continuamente a mejorar las condiciones en las que ejercían su autoridad. Las numerosas quejas de las que hemos hablado anteriormente obedecen a esta dinámica. Siempre y cuando el sistema colonial lo permitiese, los caciques recurrían a aquellas herramientas jurídicas, económicas, políticas e incluso culturales que tenían a su alcance para acrecentar su prestigio, su poder y, por consiguiente, su estatus. Es una dinámica que se repite frecuentemente entre las élites de la Monarquía Hispánicas durante la Edad Moderna. Los caciques, como parte de esas élites, actuaban de manera similar a como lo hacían sus homólogos españoles.

Una muestra de este comportamiento aparece reflejado en el documento conocido como "Memorial de Charcas", con fecha de $1582^{4}$. Este documento constituye una fuente de primer orden para conocer de cerca el pensamiento político de los caciques andinos en los momentos posteriores a la salida del virrey Toledo del espacio Peruano. En nuestro estudio, este documento adquiere una especial trascendencia ya que nos permite conocer de primera mano la concepción que tenían de sí mismos y de su propio estatus. El Memorial está compuesto en realidad de tres memoriales y una solicitud dirigidos al Rey de España. El primero de ellos está firmado por 24 señores nativos de cuatro de las grandes nacionalidades del Altiplano ${ }^{5}$. Los dos memoriales restantes y la solicitud llevan la rúbrica de don Fernando de Ayavire y Velasco, señor principal de Sacaca, en la zona de influencia de Potosí (GRAÑA, 2001). Los cuatro documentos, con independencia de su contenido, comparten un objetivo común: protestar contra los agravios provocados por el sistema toledano y pedir la restitución de los privilegios, que según ellos, poseían en época prehispánica.

Junto con las quejas habituales contenidas en este tipo de memoriales - elevada cuantía de las tasas, reparto desigual de tierras o la dureza de la mita entre otros - en el Memorial quedan recogidas algunas peticiones de especial relevancia en cuanto a que aluden directamente al estado de la autoridad de los caciques en 1582.

${ }^{4}$ El Memorial, también llamado "Crónica Inédita de 1582", fue hallado en la década de 1960 por Waldemar Espinoza Soriano en el Archivo General de Indias de Sevilla, España. La primera publicación data de 1969 aunque ha sido reproducido en diferentes ediciones a lo largo de las últimas décadas

${ }^{5}$ Los Charcas, Caracarás, Chuis y Chichas 
Respecto al estado de los privilegios de los caciques andinos destacamos el siguiente comentario:

\begin{abstract}
Al día de hoy no nos tratan conforme a la calidad de nuestras personas, especialmente a los señores naturales de a diez mil indios [es decir, a los "caciques principales"][...]. Que seamos concedidos todos los privilegios, gracias, franquezas y libertades que a los hijosdalgo se le deben concedidas (CLAROS ARISPE, 2011, p.31).
\end{abstract}

A pesar de que al inicio de este trabajo hemos señalado que la nobleza de los caciques principales fue equiparada a la de los hidalgos castellanos, comprobamos que en la práctica gozaban de menores ventajas. Mientras que los hidalgos peninsulares y todos sus hijos estaban exentos de tributar a la Corona, en las familias nobles indígenas, únicamente el primogénito varón gozaba de la exención fiscal así como de la asistencia a la mita (DÍAZ DE REMENTERÍA, 1977). El resto de los hijos del cacique principal debían tributar a la Corona aunque quedaban liberados de la mita. No ocurría lo mismo con los hijos de los caciques de niveles inferiores que estaban obligados tanto a pagar impuestos como a servir como mitayos ${ }^{6}$.

La nobleza castellana era, sin lugar a dudas, el espejo en el que se miraban los caciques andinos. Las comparaciones con ese segmento social son constantes, dejando claro que el objetivo era obtener las mismas prebendas que disfrutaba la aristocracia titulada española:

\begin{abstract}
Porque siendo nosotros señores principales de vasallos [...] como en España los duques, condes y marqueses antes de los ingas y después de ellos, nos han quitado totalmente el señorío que teníamos [sobre] nuestros súbditos y vasallos, de lo cual recibimos notorio agravio. Suplicamos a Vuestra Majestad que sea servido de mandarlo remediar haciéndonos mercedes como a señores y caciques principales, en franquezas y libertades y acrecentándonos salarios conforme a la calidad y gravedad de nuestras personas (CLAROS ARISPE, 2011, p.35).
\end{abstract}

Varias ideas interesantes se desprenden de este párrafo. En primer lugar, el hecho de equipararse con la alta nobleza española - duques, condes y marqueses - es a nuestro entender un intento claro de mejorar su estatus a través de la comparación directa. Los caciques no se conformaban únicamente con el reconocimiento de su nobleza, sino que

${ }^{6}$ Provisión del Virrey del Perú, según la ordenanza del virrey Toledo, solamente el hijo mayor del cacique principal sea reservado del tributo y la mita. Lima 3-XII-1603. Archivo y Biblioteca Nacionales de Bolivia, Audiencia de La Plata - Expedientes Coloniales / 31. Fols. 313-314. 
utilizaban el sistema legal hispano solicitando al monarca la concesión de mercedes para consolidar y acrecentar su estatus en el orden virreinal. Muestra de ello se puede comprobar en la última cita del párrafo, en el que los propios caciques lamentan la infravaloración que están sufriendo y solicitan un mayor salario en consonancia con la dignidad que merecen sus personas.

Para reforzar sus peticiones, los caciques recordaban a la Corona la importancia de su posición dentro del funcionamiento de la dinámica económica y religiosa del virreinato:

Sin ellos [refiriéndose en tercera persona a sí mismos] no se podría hacer ninguna cosa así en lo tocante a la tasa como para la doctrina cristiana y también para acudir con todo el recaudo de indios a la Villa de Potosí y al asiento de Porco [...] a donde somos obligados a dar indios (CLAROS ARISPE, 2011, p.36).

Los propios caciques eran plenamente conscientes de que jugaban un rol de suma importancia a la hora de llevar a cabo las políticas extractivas del Estado. Este fragmento revela que la nobleza nativa tenían una noción sólida de su posición de poder en el entramado colonial y que no tenían reparos en jugar la baza de su influencia sobre la población nativa para conseguir una mejora de sus condiciones por parte de la Corona.

Quizá uno de los motivos de descontento que más interés despertó entre la nobleza nativa es la falta del reconocimiento de su estatus por parte de las élites españolas. Los señores andinos se sentían discriminados - e incluso maltratados - debido a que su jerarquía apenas era respetada por el resto de autoridades españoles atendiendo a razones étnicas:

\footnotetext{
Porque en esta tierra los jueces y justicias de Vuestra Majestad y los alcaldes y alguaciles mayores y menores no miran ni tienen consideración si somos caballeros y señores de naturales de esta tierra e hijosdalgo, antes nos dan y castigan corporalmente por causas livianas con palos y nos azotan en las picotas y rollos y afrentándonos cada día y dándonos de bofetones y echándonos en las cárceles pero que si fuéramos esclavos (CLAROS ARISPE, 2011, p.38).
}

Únicamente con el reconocimiento explícito de sus privilegios por la Corona podrían llegar a ser respetados por el resto de autoridades españolas, algo que ambicionaban los caciques andinos y que durante el siglo XVII constituiría uno de sus grandes caballos de batalla en su empeño por afianzar su estatus de privilegio en los esquemas de poder de la llamada república de blancos. 


\section{VALORACIONES FINALES}

La primera reflexión que podemos alcanzar tras abordar este trabajo es que las élites indígenas, especialmente las situadas en un plano regional, no fueron desmanteladas tras el proceso de conquista sino que más bien reforzaron su poder e influencia sobre sus súbditos al ser consideradas un elemento valioso y, lo que es más importante, necesario para la extensión de la colonia en el territorio andino. De este modo, lo que a priori podría parecer un proceso dramático y de ruptura como es una conquista territorial y la sustitución de un modelo de gobierno de tipo imperial incaico por otro colonial de tipo europeo, supuso en realidad una oportunidad para las élites nativas locales de reforzar su estatus a través de la inserción y adaptación de su prestigio jerárquico a los esquemas virreinales. Como hemos visto, el hecho de servir de nexo de unión entre las autoridades hispanas y la población india, les situó en una posición de prestigio, consolidando su nobleza a través de la legalización de su estatus jurídico por parte de la Corona y consiguiendo mantener la legitimidad que emanaba de sus sujetos al no ver desvirtuadas sus funciones tradicionales para con sus comunidades. Esta postura queda perfectamente reflejada en palabras del propio virrey Toledo, quien llegó a asegurar que "no se puede gobernar a estos naturales sin que los caciques sean los instrumentos de la ejecución" (ASSADOURIAN, 1994, p. 163).

Esta doble proyección de los caciques fue clave para conservar su poder y extender su presencia a un contexto más amplio, estableciendo vínculos con las autoridades superiores hispanas. Dichos vínculos fueron, en esencia, relaciones estipuladas a partir de la política económica de extracción fiscal y metalífera de la Corona en América. Con las responsabilidades de recaudar los tributos y organizar a los mitayos, los caciques sirvieron como agentes coloniales cumpliendo una función de gran trascendencia. Ello no sólo les permitió asumir competencias que reforzarían de manera significativa su poder, sino que les permitió establecer un contacto más estrecho con las élites españolas para, de este modo, obtener mayores beneficios tanto para ellos como para sus comunidades.

A pesar de que determinados caciques pudieron establecer relaciones con cargos de prestigio dentro de la administración virreinal, estos vínculos nunca se establecieron de igual a igual, sino que destacaron por su naturaleza asimétrica. Pese a ver reconocido su poder, la 
nobleza nativa nunca consiguió equipararse a la aristocracia española en el Perú, ni mucho menos introducirse en las altas esferas de poder y gobierno del virreinato. Con todo, los caciques trataron de mejorar su estatus a través de la reinterpretación de sus esquemas de prestigio y, por extensión, de la readaptación de su identidad cultural en asimilación con la de las élites gobernantes.

Las frecuentes quejas recogidas en memoriales como el de 1582 muestran a unos caciques disconformes con su situación, recurriendo al sistema legal hispano para mejorar en cualquiera de las formas en las que fuera posible. En nuestra opinión, esta actitud responde a un hecho significativo. Entendiendo el poder de los curacas, no como un estado estable, sino como el producto de una revalidación continuada, podemos comprender que las demandas de los caciques obedecían a su deseo de obtener una certificación suplementaria de su estatus. En el trabajo hemos hablado de ambición como condición que define al desempeño del cargo de cacique. Y realmente fue así. Se trata, por tanto, de ambición por conseguir un mayor apoyo a su poder, ya que este, como hemos visto, no era estable sino que se sustentaba sobre diversos reconocimientos que precisaban ser renovados o, por extensión, acrecentados.

En este trabajo hemos tratado de demostrar que el estudio del poder de la nobleza nativa precisa de una reivindicación de la figura de los caciques, no como víctimas de la conquista y del proceso colonial, sino como partes fundamentales en el funcionamiento de la misma, cuyo rol fue reconocido y reconocible en la estructura de poder virreinal. Analizando los comportamientos de los señores étnicos en base al ejercicio y mantenimiento de su autoridad seremos capaces de llegar a desentrañar su verdadera repercusión y aproximarnos a una compresión más completa de la sociedad colonial en su conjunto.

\section{BIBLIOGRAFÍA}

ALAPERRINE-BOUYER, M. Recurrencias y variaciones de la imagen del cacique. En Lavallé, Bernard (Ed.) Máscaras, Tretas y Rodeos del Discurso Colonial en los Andes. Lima; Instituto Francés de Estudios Andinos, p. 189-209, 2005.

ARCHIVO HISTÓRICO - Casa Nacional de la Moneda (Potosí). Sección Cajas Reales. Doc. 72. Padrón de Mitayos de 1600. 
ASSADOURIAN, C. S. Transiciones hacia el sistema colonial andino. Lima: Instituto de Estudios Peruanos, 1994.

BUNSTER, C. Las autoridades indígenas y los símbolos de prestigio. Andes, n. 12, 139,2001 .

CHOQUE CANQUI, R. El papel de los capitanes de indios de la provincia de Pacajes en el entero de la mita de Potosí. Revista Andina, v. 1, p. 117-125, 1983.

CLAROS ARISPE, E. El Memorial de Charcas. Ciencia y Cultura, n. 27, p. 25-62, 2011.

DE LA PUENTE LUNA, J. C. Los curacas hechiceros de Jauja. Batallas mágicas y legales en el Perú colonial. Lima: Fondo Editorial de la Pontificia Universidad Católica de Perú, 2007.

DÍAZ DE REMENTERÍA, C. J. El cacique en el Virreinato del Perú: estudio históricojurídico. Sevilla: Publicaciones de la Universidad de Sevilla. 1977.

FOUCAULT, M. El sujeto y el poder. Revista Mexicana de Sociología, v. 50, n. 3, p. 3-20, 1988.

GAREIS, I. Los rituales del Estado colonial y las élites andinas. Bulletin de L'Institut Français d'Estudes Andines,v. 37 (1), p. 97-109, 2007.

GRAÑA, M. J. La verdad asediada. Discursos de y para el poder. Escritura, institucionalización y élites indígenas sur andinas. Charcas. Siglo XVI.”. Andes, n. 12, p. 1$14,2001$.

LÓPEZ BELTRÁN, C. La mita gasta muchos indios. Mineros y campesinos del siglo XVII en las minas de Potosí. Cuadernos Hispanoamericanos: los complementarios, n. 7-8, p. 59-86, 1991. 
MONSALVE, M. Curacas pleitistas y curas abusivos: conflicto, prestigio y poder en los Andes coloniales, siglo XVII” En Cahill, D. y Tovías B. (Eds.). Elites Indígenas en los Andes. Nobles, caciques y cabildantes bajo el yugo colonial. Quito: Abya-Yala, p.159-174, 2003.

PACHECO BALANZA, M. Entre la legalidad y la legitimidad. El posicionamiento político del cacique yampara Francisco Aymoro II en Charcas,p.1570-1620. Sucre: ABNB, 2012.

POLONI-SIMARD, J. Historia de los indios en los Andes, los indígenas en la historiografía andina: análisis y propuestas. Nuevo Mundo, Mundos Nuevos. Agosto, 2005.

PONCE LEIVA, P. Por mucho amor que les he tenido. Sensibilidades y dinámicas sociales en Quito a mediados del siglo XVII" En Bernabeú, S. y Langue, F. (coords.) Fronteras y Sensibilidades en las América,Aranjuez: Doce Calles, p. 21-44, 2011.

RAMÍREZ, S. E. La legitimidad de los curacas en los Andes durante los siglos XVI y XVII. Boletín del Instituto Riva-Agüero, n. 24, p. 467-492, 1997.

ROSAS LAURO, C. Entre la satanización y la idealización. La figura del curaca en la historiografía andina contemporánea. Histoire(s) de l'Amerique latine, v. 9, p. 1-36, 2009.

SAIGNES, T. De la Borrachera al Retrato: los Caciques Andinos entre dos legitimidades (Charcas).Revista Andina., n. 13, p. 82-127, 1987.

SÁNCHEZ ALBORNOZ, N. Indios y tributos en el Alto Perú. Lima: Instituto de Estudios Peruanos, 1978.

STERN, S. J., Los pueblos indígenas del Perú y el desafío de la conquista española. Madrid: Alianza Editorial, 1982.

SPALDING, K. De Indio a Campesino. Cambios en la estructura social del Perú colonial. Lima. Instituto de Estudios Peruanos, 1974. 
SPALDING, K. Resistencia y adaptación: el gobierno colonial y las élites nativas. Allpanchis, n.17-18, v. XV, p. 5-21, 1981.

Recebido em 26/04/2017. Aceito em 09/11/2017. Publicado em 29/12/2017.

DOI: 10.11606/issn.1676-6288.prolam.2017.131585 ISSN: $1676-6288$ 